\title{
Indoor Radon Concentration and Ventilation Rate in Some Elementary Schools in Ibadan, Nigeria
}

\author{
Emmanuel Akinbami Oyelade ${ }^{1}$, Alaba Tolulope Agbele ${ }^{2,3, *}$, Olufisayo Olalekan Awe ${ }^{4}$, Kalid Abayomi Bello ${ }^{3}$, Victor \\ Shegun Oluwatuyi ${ }^{5}$ \\ ${ }^{I}$ Department of Science Education, Federal University of Lafia, Nigeria \\ ${ }^{2}$ Department of Medical Physics, Tehran University of Medical Science, Iran \\ ${ }^{3}$ Department of Basic Medical Sciences, College of Health Sciences and Technology, Ijero-Ekiti, Nigeria \\ ${ }^{4}$ Department of Basic Sciences (Physics Electronics Unit), Babcock University Ilishan Remo, Nigeria \\ ${ }^{5}$ Department of Public Health, College of Health Sciences and Technology, Ijero-Ekiti, Nigeria \\ * Corresponding author
}

\begin{abstract}
Introduction: This study aimed to find the correlation between indoor radon concentration and ventilation rate in some selected elementary schools in Ibadan, Southwestern Nigeria. The schools and the rooms were selected on the basis of different natural ventilation conditions.
\end{abstract}

Materials and methods: The measurements of indoor radon concentrations were performed by using a passive diffusion cup technique fitted with CR-39 detectors. The values of indoor radon concentration vary from $103 \mathrm{~Bq} / \mathrm{m}^{3}$ to $362 \mathrm{~Bq} / \mathrm{m}^{3}$ with an average value of $196 \mathrm{~Bq} / \mathrm{m}^{3}$. However, the value of effective dose ranged between $0.65 \mathrm{mSvy}^{-1}$ and $2.28 \mathrm{mSvy}^{-1}$, with an average value of $0.45 \mathrm{mSvy}^{-1}$. The approximate natural ventilations rates of the selected rooms were calculated using ventilation formulae. The measurements were aimed to investigate the effect of ventilation rate on indoor radon concentration.

Results: The results of the present study indicate that there is a high correlation between radon concentration and ventilation rate. Ventilation rate is inversely proportional to indoor radon concentration. By and large, all the results of indoor radon concentration are found to be lower than the recommended action level $\left(1000-1500 \mathrm{~Bq} / \mathrm{m}^{3}\right)$ for workplaces by the International Commission of Radiation Protection (ICRP). Also, the values of the effective dose levels are found to be lower than the average value of $10 \mathrm{mSvy}^{-1}$.

Conclusion: Radon concentration is expected to be higher during the cold season when ventilation would be low. Therefore, there is need to improve on ventilation and other means of mitigation in some classrooms where radon concentrations were relatively high.

Keywords: Radon, Radiation protection, Environmental radiation, Ventilation, Radioactivity

\section{INTRODUCTION}

$\mathrm{R}$ adon is a naturally occurring gas that seeps into buildings from the surrounding soil. The United State of Environmental Protection Agency ranks indoor radon among the most serious environmental health problems facing us today. After smoking, it is the second leading cause of lung cancer in the United States causing an estimated twenty-one thousand $(21,000)$ lung cancer deaths a year $[1,2]$. Since the 1980s, a large number of studies have directly examined the relationship between indoor radon concentration and lung cancer in the general population. Radon gas decays into radioactive particles that can get trapped in the lung when breathing. The risk of getting lung cancer from radon depends mostly on three factors: the level of radon, the duration of exposure and their smoking habits.

Radon in schools can be a significant source of exposure to the people who spend most of their time there, specifically staff and students. EPA recommends that all schools be tested for radon because the school environment affects a child's health and ability to learn, and could be the determinative factor for some children as to whether they succeed in school or fail [3] the effects of radon exposure is long- term, before its effects become manifest in adult, they might have died. Nevertheless, pupils with elongated life span must be prevented from radon exposure [4].

In recent years, several studies have shown that radon concentration and its decay products in buildings show large temporal and local fluctuations due to changes in temperature, pressure, humidity, building materials and ventilation rates among others. All buildings built with stones and soils are polluted to some extent with radon, but in certain geographical areas, the rate of seepage of radon from the soil is much faster than elsewhere. The occurrence of radon in soils relates with the amount of uranium $\left({ }^{238} \mathrm{U}\right)$ in sub-soil and with the geological structure of the area.

\section{Geology of Ibadan}

Ibadan, capital city of Oyo state, Nigeria, lies within longitude 3.917313 and latitude 7.401962 as shown in figure 1. It has a total population of about $2,559,853$ at 2006 census. It has a land mass of about 1,189 square meters. It is the largest city in West Africa and the second largest city in Africa after Cairo. The major rocks types in Ibadan include; quartzite/quartz, schist, pegmatite banded gneiss, granite gneiss, migrated gneiss and augends with minor intrusions of dolerite, aplite, quartz veins and pegmatite [5]. The city of Ibadan is naturally drained by four rivers with many tributaries: Ona River in the North and West; Ogbere River 
towards the East; Ogunpa River flowing through the city and Kudeti River in the central part of the metropolis. The city ranges in elevation from $150 \mathrm{~m}$ in the valley area, to $275 \mathrm{~m}$ above sea level on the major north-south ridge which crosses the central part of the city [6].

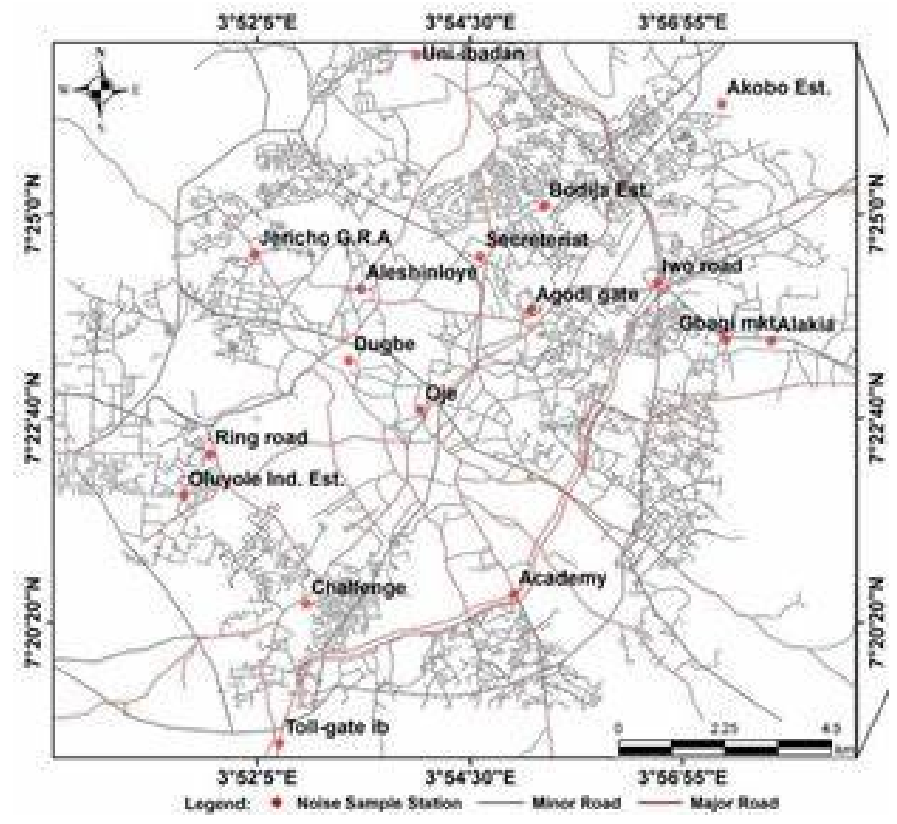

Figure 1. Map of Ibadan metropolis

\section{MATERIALS AND METHODS}

\section{Determination of Radon Concentration}

The CR-39 detectors were distributed into five selected elementary schools in Ibadan, Oyo State Nigeria. This was done between February and April when the weather was relatively warm. The detectors were exposed for a period of 90 days in the classrooms selected based on different ventilation rates. The detectors were hung at a height of about $1.2 \mathrm{~m}$ above the floor as a representative of breathing height inside the classrooms. At the end of the exposure time, the detectors were retrieved and etched using 6.25 moles of sodium hydroxide solution at $90{ }^{\circ} \mathrm{C}$ for 3 hours. The tracks were counted using an optical microscope at $400 \mathrm{X}$ magnification. Tracks density was converted into radon concentration using equation 1 . The potential alpha equilibrium concentration, working level month, effective dose to the lung and excess lifetime cancer risk were calculated respectively using equations $2,3,4$ and 5 .

Radon Concentration $\left(\mathrm{R}_{\mathrm{n}}\right)=\frac{\mathrm{T}_{\mathrm{D}}}{\mathrm{tXCF}}$

$\mathrm{PAEC}(\mathrm{WL})=\frac{F X R_{n}}{3700}$

Working level month $(\mathrm{WLM})=\mathrm{WL} X \frac{T}{170 \text { hour }}$

Effective dose $(\mathrm{H})=\mathrm{Rn} \times \mathrm{F} \times \mathrm{O} \times \mathrm{T} \times \mathrm{DCF}$

Excess lifetime cancer risk $(\mathrm{ELCR})=\mathrm{H} \times \mathrm{DL} \times \mathrm{RF}$ where calibration factor $(\mathrm{CF})=1$ trackmm $\mathrm{km}^{-2} / 1.8 \mathrm{kBq} / \mathrm{m}^{3}$, exposure time $(\mathrm{t})=90$ days, equilibrium factor $(\mathrm{F})=0.4$, Hours in a year $(\mathrm{T})=1825 \mathrm{~h}$, Occupancy factor $(\mathrm{O})=0.2$, dose conversion factor $(\mathrm{DCF})=0.9 \mathrm{nSv}\left(\mathrm{Bq} / \mathrm{m}^{3}\right)$, life expectancy $(\mathrm{DL})=70$ years and the risk factor $(\mathrm{RF})=0.055$ $\mathrm{Sv}^{-1}$

\section{Calculation of Natural Ventilation Rate}

Radon gas seeps into the rooms from cracks in the wall and floor of the room which can become accumulated if the ventilation of the room is poor. Ventilation is more difficult in cold season because windows and doors are mostly shot, which could increase the concentration of indoor radon [7]. The natural ventilation was calculated by using equations 6,7, and 8. In doing this, parameters such as height of the building, area of opening of doors and windows, volume of the rooms and air flow speed were noted. The ventilation rates were estimated and presented in column 2 of table 1 . The ventilation rates were express in a unit called air change rate per hour $\left(\mathrm{ach}^{-1}\right)$. One air change per hour is the amount of ventilation needed to fill the room once in an hour [8].

$$
\begin{aligned}
& \text { Ventilation rate per person } \\
& \frac{\text { Air chang rate per hour } X D X h}{60} \\
& \text { Air change rate per hour }=\frac{60 Q}{\text { volume of the room }} \\
& Q=\text { air flow velocity } \mathrm{x} \text { area of opening }
\end{aligned}
$$

Where D is the occupant density i.e. occupants per squared meters and $h$ is the height of the ceiling. The air flow velocity was measured by a digital anemometer placed at every opening; the windows and the doors

\section{RESULTS AND DISCUSSIONS}

Table 1 shows the ventilation rate, radon concentration, working level, working level month, effective dose and excess lifetime lung cancer risk for the study area. The indoor radon concentration ranged from $103 \mathrm{~Bq} / \mathrm{m}^{3}$ to $362 \mathrm{~Bq} / \mathrm{m}^{3}$ with an average of $196 \mathrm{~Bq} / \mathrm{m}^{3}$. This is low when compared with 1500 $\mathrm{Bq} / \mathrm{m}^{3}$, the action level recommended for work places. The average value of effective dose is $1.24 \mathrm{mSvy}^{-1}$ which is inferior to the ICRP reference level of 3-10 $\mathrm{mSvs}^{-1}$ [9] while excess lung cancer risk was calculated to be 4.77 (MPY) $^{-1}$.

The average ventilation rate was calculated as $1.40 \mathrm{ach}^{-1}$. This is above $(0.35-0.60) \mathrm{ach}^{-1}$ recommended by American Society of Heating, Refrigerating and Air-Conditioning Engineers (ASHRAE) for leaving rooms [10]. Equation 9 was used to analysis the relationship between radon concentration and ventilation rate.

$\mathrm{Y}=\beta_{0}+\beta_{1} \mathrm{X}$

Where $\mathrm{Y}$ is the dependent variable i.e. radon concentration, $\mathrm{X}$ is the independent variable i.e. ventilation rate, and $\beta_{0}$ and $\beta_{1}$ are the respective intercept and slope regression coefficient. Figure 2 is a graph showing correlation between radon concentration and ventilation rate. From the graph, a strong 
International Journal of Research and Scientific Innovation (IJRSI) | Volume VII, Issue VII, July 2020 | ISSN 2321-2705

positive correlation between radon concentration and ventilation rate was observed $\left(\mathrm{R}^{2}=0.77\right)$. $\mathrm{R}$-squared value of 0.77 indicates that ventilation rate is the key factor upon which radon concentration depends. This result is similar to that obtained by Ashok [11] where $\mathrm{R}$ squared value was gotten to be 0.66 . Figure 3 is a bar chart that established an inverse relationship between indoor radon concentration and ventilation rate.

Table 1: Distribution of Radon Concentration and Ventilation Rate in all Selected Schools

\begin{tabular}{|c|c|c|c|c|c|c|}
\hline Detectors' No & $\begin{array}{c}\text { Ventilation rate } \\
\text { (ach)-1 }\end{array}$ & $\begin{array}{c}\text { Radon Conc. } \\
\left(\mathrm{Bqm}^{-3}\right)\end{array}$ & PAEC (mWL) & $\operatorname{WLM}\left(y^{-1}\right)$ & $\begin{array}{c}\begin{array}{c}\text { Effective dose } \\
\left(\mathrm{mSvy}^{-1}\right)\end{array} \\
\end{array}$ & $\operatorname{ELCR}(M P Y)^{-1}$ \\
\hline J54819 & 2.52 & 103 & 11.14 & 0.46 & 0.65 & 2.50 \\
\hline J54834 & 2.49 & 103 & 11.14 & 0.46 & 0.65 & 2.50 \\
\hline J54813 & 2.46 & 103 & 11.14 & 0.46 & 0.65 & 2.50 \\
\hline J52971 & 2.20 & 103 & 11.14 & 0.46 & 0.65 & 2.50 \\
\hline J55115 & 2.81 & 103 & 11.14 & 0.46 & 0.65 & 2.50 \\
\hline J55199 & 1.64 & 103 & 11.14 & 0.46 & 0.65 & 2.50 \\
\hline J54799 & 1.54 & 155 & 16.76 & 0.69 & 0.98 & 3.77 \\
\hline J54815 & 1.45 & 155 & 16.76 & 0.69 & 0.98 & 3.77 \\
\hline J54907 & 1.42 & 155 & 16.76 & 0.69 & 0.98 & 3.77 \\
\hline J54929 & 1.20 & 155 & 16.76 & 0.69 & 0.98 & 3.77 \\
\hline J54112 & 1.38 & 207 & 22.38 & 0.92 & 1.31 & 5.03 \\
\hline J54898 & 1.36 & 207 & 22.38 & 0.92 & 1.31 & 5.03 \\
\hline J54909 & 1.32 & 207 & 22.38 & 0.92 & 1.31 & 5.03 \\
\hline J55187 & 1.28 & 207 & 22.38 & 0.92 & 1.31 & 5.03 \\
\hline J55194 & 1.20 & 207 & 22.38 & 0.92 & 1.31 & 5.03 \\
\hline J55415 & 1.11 & 207 & 22.38 & 0.92 & 1.31 & 5.03 \\
\hline J54848 & 1.01 & 207 & 22.38 & 0.92 & 1.31 & 5.03 \\
\hline J54782 & 0.99 & 258 & 27.89 & 1.15 & 1.63 & 6.27 \\
\hline J54881 & 0.97 & 258 & 27.89 & 1.15 & 1.63 & 6.27 \\
\hline J54917 & 0.96 & 258 & 27.89 & 1.15 & 1.63 & 6.27 \\
\hline J54970 & 0.90 & 258 & 27.89 & 1.15 & 1.63 & 6.27 \\
\hline J55131 & 0.89 & 258 & 27.89 & 1.15 & 1.63 & 6.27 \\
\hline J55237 & 0.87 & 258 & 27.89 & 1.15 & 1.63 & 6.27 \\
\hline J55162 & 0.72 & 310 & 33.51 & 1.38 & 1.96 & 7.53 \\
\hline J55224 & 0.66 & 362 & 39.14 & 1.61 & 2.28 & 8.80 \\
\hline Mean \pm SD & $1.41 \pm 0.60$ & $196 \pm 70$ & $21.22 \pm 7.58$ & $\mathbf{0 . 8 7} \pm \mathbf{0 . 3 1}$ & $1.24 \pm 0.44$ & $4.77 \pm 1.71$ \\
\hline
\end{tabular}

Corellation graph between indoor radon Conc. and ventilation rate $y=-102.75 x+341.57$

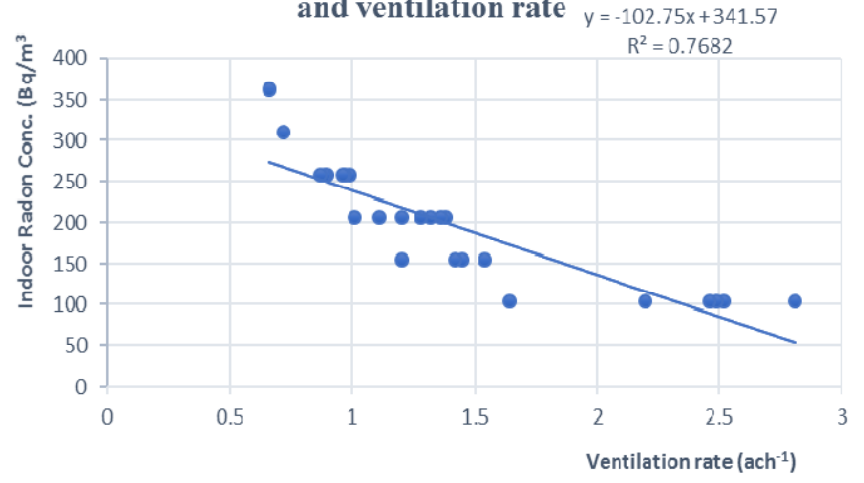

Figure 2: Comparison between ventilation rate and indoor radon concentration using
Indoor radon Conc. and ventilation rate

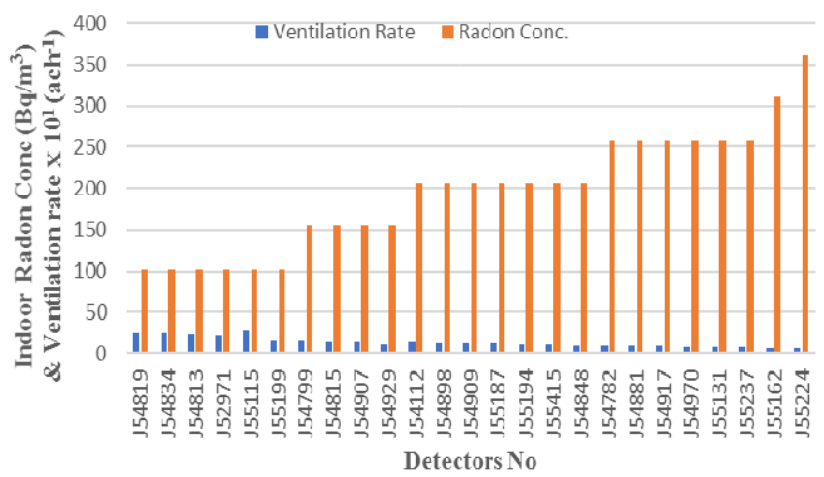

Figure 3. Comparison Between Ventilation Rate and Indoor Radon Concentration Using Bar Chart 


\section{CONCLUSION}

Our results show a positive correlation between indoor radon concentration and ventilation rate. The results also show that the radon concentration, effective dose and excess lung cancer risk due to inhalation of radon by teachers and pupils of the selected schools were insignificant between February and April when the investigation was carried out. Radon concentration is expected to be higher during cold season when ventilation would be low. Therefore, there may be need to improve on ventilation and other means of mitigation in some classrooms where radon concentrations were relatively high. It is recommended that further studies be carried out to cover cold and dry seasons in order to establish the effects of seasonal variability on ventilation rate and its consequence effect on radon concentration in the study area. It is also recommended that the scope of the study be expanded to cover more schools in Ibadan metropolis and Nigeria as a whole.

\section{ACKNOWLEDGEMENTS}

The authors are grateful to the teachers, students and security personnel of the selected schools for the approval, assistance and cooperation received from them during the period the detector were exposed in their schools.

\section{CONFLICT OF INTEREST}

The authors declared no conflicts of interest.

\section{FINANCIAL DISCLOSURE}

The authors declared that this study has received no financial support.

\section{REFERENCES}

[1]. Environmental PU. Agency (2003). EPA assessment of risks from radon in homes. EPA 402-R-03-003. Washington.

[2]. World Health Organization (2009). WHO handbook on indoor radon: a public health perspective: World Health Organization.

[3]. Synnott H, Fennell S, Pollard D, Colgan P, Hanley O, O'Colmain M, et al., (2004). Radon in Irish primary and post-primary schools. The results of a national survey. Radiological Protection Institute of Ireland.

[4]. Obed R, Oyelade E, Lateef H., (2018). Indoor radon levels in some selected nursery and primary schools in Ibadan, Oyo State, Nigeria. Journal of radiation research and applied sciences. 2018;11(4): p.379-382.

[5]. Okunlola O, Adeigbe O, Oluwatoke O., (2009). Compositional and petrogenetic features of schistose rocks of Ibadan Area, southwestern Nigeria. Earth Sciences Research Journal. 2009;13(2): p.119-133.

[6]. Olayinka A, Olayiwola M., (2001). Integrated use of geoelectrical imaging and hydrochemical methods in delineating limits of polluted surface and groundwater at a landfill site in Ibadan area, southwestern Nigeria. Journal of Mining and Geology. 2001;37(1): p. 53-68.

[7]. Barescut J, Lariviere D, Stocki T, Chang B, Kim Y, Song M, et al., (2011). Measurement of indoor radon concentration and actual effective dose estimation of schools at high radon area in Korea. Radioprotection. 2011;46(6):S91-S.

[8]. McQuiston FC, Parker JD, Spitler JD., (2004). Heating, ventilating, and air conditioning: analysis and design: John Wiley \& Sons; 2004.

[9]. International Commission on radiological Protection ICRP., (2014). Radiological protection against radon exposure, ICRP Publication 126. Ann ICRP. 2014;43(3).

[10]. Wallace L, Ott W., (1996). Air exchange rate experiments in a detached house using a continuous monitor. An Annual Meeting of the Society for Risk Analysis and the International Society of Exposure Analysis, New Orleans, LA 1996.

[11]. Ashok G, Nagaiah N, Shiva Prasad N., (2012). Indoor radon concentration and its possible dependence on ventilation rate and flooring type. Radiation protection dosimetry. 2012;148(1):92100. 